\title{
Apo B/Apo A-I Ratio in Central and Peripheral Arterial Diseases
}

\section{perspectiva}

\author{
LUCIANA M. LIMA \\ Maria das Graças Carvalho \\ ADRIANO DE P. SABINO \\ ANA P.L. MOTA \\ ANA P. FERNANDES \\ MARINEZ O. SOUSA
}

Faculty of Pharmacy, Federal University of Minas Gerais, Belo Horizonte, MG.
Recebido em 19/01/07 Revisado em 08/05/07 Aceito em 04/07/07

\section{ABSTRACT}

Background: The apo B/apo A-I ratio represents the balance between atherogenic particles, rich in apo $B$, and the antiatherogenic ones, apo A-I rich. This study investigated the association between atherosclerotic diseases in different anatomical sites and apo B/apo A-I ratio. Methods: Lipids, lipoproteins, and apolipoproteins $\mathrm{A}-\mathrm{I}$ and $\mathrm{B}$ were assessed in 30 subjects with coronary artery disease (CAD), 26 with ischemic stroke (IS), 30 with peripheral arterial obstructive disease (PAOD), and 38 healthy subjects (controls). Results: HDLc and Apo A-I were significantly lower in PAOD and CAD groups, respectively, than in other groups. Significantly higher levels of triglycerides were observed for CAD and PAOD groups than for controls. Apo B was significantly higher in IS group than in control and PAOD groups. The apo B/apo A-I ratio showed significantly higher in CAD and IS groups when compared to control and PAOD groups $(p<$ 0.001). Conclusion: The apo B/apo A-I ratio was important for identifying an increased trend for coronary and cerebral atherosclerosis. In spite of the increased trend for apo B/apo A-I ratio in IS and CAD groups, the studied variables cannot be considered in an isolated way, given as those parameters were analyzed together by a binary logistic regression, no association has been demonstrated. (Arq Bras Endocrinol Metab 2007;51/7:1160-1165)

Keywords: Apolipoproteins A-I and B; Coronary artery disease; Ischemic stroke; Peripheral arterial obstructive disease

\section{RESUMO}

Índice Apo B/Apo A-I nas Doenças Arteriais Central e Periférica.

Introdução: $\mathrm{O}$ índice apo B/apo A-I representa o balanço entre partículas de colesterol potencialmente aterogênicas ricas em apo $B$ e partículas antiaterogênicas ricas em apo A-I. O objetivo deste estudo foi investigar a associação entre doenças ateroscleróticas em diferentes sítios anatômicos e o índice apo B/apo A-I. Métodos: Lípides, lipoproteínas e apolipoproteínas A-I e $B$ foram quantificados em 30 indivíduos apresentando doença arterial coronariana (DAC), 26 com acidente vascular cerebral (AVC), 34 apresentando doença arterial obstrutiva periférica (DAOP) e 38 indivíduos hígidos (grupo controle). Resultados: HDLc e apo A-I apresentaram-se significativamente mais baixos nos grupos DAOP e DAC, respectivamente, quando comparados com os demais grupos. Níveis de triglicérides foram significativamente mais elevados nos grupos DAC e PAOD quando comparados com o grupo controle. Apo $B$ foi significativamente mais elevada no grupo AVC quando comparado com os grupos controle e DAOP. O índice apo B/apo A-I se mostrou significativamente elevado nos grupos DAC e AVC quando comparados com os demais $(p<0,001)$. Conclusão: $O$ índice apo B/apo A-I foi importante para identificar uma tendência aumentada para aterosclerose coronariana e cerebral. No entanto, os parâmetros avaliados não podem ser considerados de forma isolada, considerando que nenhuma associação foi demonstrada quando os dados foram analisados pelo modelo de regressão logística binária. (Arq Bras Endocrinol Metab 2007;51/7:1160-1165)

Descritores: Apolipoproteínas A-I e B; Doença arterial coronariana; Acidente vascular cerebral; Doença arterial obstrutiva periférica 
A THEROSCLEROSIS IS, IN PART, a chronic inflammatory process involving the formation of atheroma plaques that may suffer rupture or erosion, thus provoking the thrombus formation (1). Among the most important thrombotic events are myocardial infarction (MI), ischemic stroke (IS), transient ischemia, and peripheral arterial obstructive disease (PAOD) (2). Epidemiological, clinical, and therapeutical studies show evidence of a correlation between the alteration in the lipid profile and atherosclerosis (3). However, a large number of patients who develop atherosclerotic diseases present normal lipid levels (4), demonstrating that, despite the enormous contribution of the dyslipidaemias to the development of atherosclerosis, other factors are also responsible for its progression.

Apolipoproteins A-I and B plasma levels have been described as better predictors of atherosclerotic diseases than the lipid and lipoprotein concentrations $(5,6)$. The apo B/apo A-I ratio represents the balance between atherogenic particles, rich in apo B, and the antiatherogenic ones, apo A-I rich, and it has been shown to be a better parameter for the prediction of cardiovascular risk than the lipids, lipoproteins, and lipid ratios (7-10). Moreover, the apolipoproteins concentrations suffer little influence from biological variables when compared with lipid measurements (11-13). In contrast to the large number of studies demonstrating the predictive value of the apo B/apo A-I ratio for $\mathrm{CAD}$, few studies have examined this index in other arterial ischemic events. Therefore, the relationship between the apo $\mathrm{B} / \mathrm{apo}$ A-I ratio and IS and PAOD diseases is still not established.

This study explored the correlation of atherosclerotic diseases in different anatomical sites with apo $\mathrm{B} /$ apo A-I ratio in an attempt to encounter possible associations between clinical and biochemical abnormalities. The apo B/apo A-I ratio was also used to investigate the possible differences among patients with different risk factors, i.e., it was applied to establish a comparison between smoking and non-smoking patients, the presence or lack of hypertension, and the family history for atherosclerotic diseases.

\section{MATERIALS AND METHODS}

\section{Patients and control subjects}

The study protocol was approved by the Committee for Ethics in Research of the Federal University of Minas Gerais and the Committee for Ethics in Research of all the hospitals where patients were recruited. All subjects signed legal consent forms. Information on demographic characteristics, medical history and the presence of risk factors associated with atherosclerotic diseases, family history, and diagnostics of coronary and peripheral arterial disease were also assessed. We assessed a total of 124 male and female subjects between the ages of 11 to 68 years. CAD patients, with coronary angiography demonstrating stenosis of more than 70 percent of the luminal diameter in one or more coronary arteries, were selected in the Socor Hospital in Belo Horizonte, Minas Gerais, Brazil. IS patients were selected in the University Hospital, Federal University of Minas Gerais, Belo Horizonte, the diagnosis being confirmed by magnetic resonance or computer brain tomography. Patients with PAOD were selected in the Santa Casa Hospital of Belo Horizonte. Their diagnoses were confirmed through clinical examination and measurement of the ankle/arm index (those having values lower than 0.9 were selected) (14). Patients submitted to arterial revascularization surgery in the lower limbs were also included. The control group was composed of healthy subjects with no previous history of CAD, IS or PAOD, selected in the hospitals where patients were recruited. On the basis of clinical criteria, the subjects were divided into four groups: control $(\mathrm{n}=38)$, CAD ( $\mathrm{n}$ $=30)$, IS $(\mathrm{n}=26)$, and PAOD $(\mathrm{n}=30)$.

Subjects with renal, hepatic, autoimmune, and mieloproliferative diseases, coagulation disorders and cancer, and those in a post-operative period or immobilized during a long time, or under lipid-modifying therapy were excluded from the study. All participants with triglycerides levels above $400 \mathrm{mg} / \mathrm{dL}$ were also excluded. The patients selected for the study were diagnosed for arterial disease at least three months before the venepunction.

Smoking habits and the family history of atherosclerotic diseases were confirmed based on the recommendations of the III Brazilian Guidelines on Dyslipidaemias and Guidelines for Atherosclerosis Prevention (15). Individuals were classified as having DM2 if plasma glucose was equal to or superior then $126 \mathrm{mg} / \mathrm{dL}$ in the fasting state (performed in all subjects not previously diagnosed as having diabetes) or if individuals were receiving oral anti-diabetics or insulin (16). Hypertension was diagnosed if the systolic and/or diastolic blood pressure exceeded 140 and/or $90 \mathrm{mmHg}$ or those under antihypertensive agents (17).

\section{Samples collection}

Venous blood samples were taken from all subjects after fasting for 12 hours. They were advised not to practice vigorous physical activity and to avoid ingestion of ethanol in the 24 and 72 hours, respectively, preceding blood collection, so as to obtain biological samples from patients presenting an equilibrated metabolic state. Ten milliliters of venous blood without anticoagulant were collected from each participant using Vacutainer ${ }^{\circledR}$ System tubes (Becton-Dickinson). Samples were centrifuged at $1.100 \mathrm{~g}$ for 15 minutes for rapid serum separation. Serum aliquots were stored at $-70^{\circ} \mathrm{C}$.

\section{Laboratory measurements}

Total cholesterol (TC) and triglycerides (TG) were determined by enzymatic colorimetric methods (Randox ${ }^{\circledR}$ Cholesterol CHOD-PAP and Randox ${ }^{\circledR}$ Triglycerides GPO-PAP, 
respectively). HDLc was performed by the enzymatic elimination method (Randox ${ }^{\circledR}$ HDL Cholesterol Direct), and LDLc was estimated by the Friedewald equation.

The plasma apolipoproteins A-I and B levels were assessed using the immunoturbidimetry assay (BioTécnica ${ }^{\circledR}$, Brazil, Apolipoprotein A-I and Apolipoprotein B, respectively) in a Cobas Mira Plus (Roche ${ }^{\circledR}$ ) device as instructed by the manufacturer. In brief, the test samples are reacted with a specific antibody to human apolipoprotein A-I or B in a suitable buffer. The turbidity induced by the formation of immune complexes was measured at $340 \mathrm{~nm}$, and the values were then calculated automatically from a known standard. All of the assay steps were performed automatically by the instrument. No significant cross-reactivity or interference from other biochemical parameters has been observed for the assays (BioTécnica, Brazil). The coefficient of variation was $2.67 \%$ and $2.29 \%$ for apolipoproteins A-I and B, respectively (BioTécnica, Brazil). A commercial control-serum was used to verify the assays performance.

\section{Statistical analysis}

Data were analyzed by Sigma Stat version 1.0 software system using one-way analysis of variance (ANOVA) followed by the Tukey test. Triglycerides levels, which not presented normal distribution, were analyzed after log-transformation of the data. Categorical variables (risk factors) were analyzed by the Chi-square contingency test. Pearson's correlation coefficient was used to measure the linear association between two continuous variables. The minimum size of the sample was defined using the coefficient of variation previously described in the literature, considering a ten percent of variation around the average and with a minimum number of twenty individuals in each group. Based on the described criterion, it was possible to verify statistical differences with a $5 \%$ level of significance. To investigate possible association between both risk factors and biochemical parameters and each disease (IS, CAD, PAOD) it was performed a model of binary logistic regression.

\section{RESULTS}

\section{Baseline characteristics of the study participants}

The characterization of the groups, including sex and age, as well as the risk factors associated with atherosclerosis diseases, number of subjects, and percentage of each variable, is presented in table 1. Patients with CAD and PAOD were significantly older than controls and IS patients. For the smoking parameter, a significant difference was obtained for PAOD group as compared to IS and CAD groups $(\mathrm{p}<0.001)$, while CAD and PAOD groups showed a significant difference compared to the IS group $(\mathrm{p}<0.001)$ for hypertension. Regarding family history of atherosclerotic dis- ease, IS and CAD groups were significantly different from the PAOD group $(p<0.001)$. For diabetes mellitus, $\mathrm{CAD}$ and $\mathrm{PAOD}$ groups differed significantly $(\mathrm{p}$ $<0.001)$.

\section{Biochemical analysis}

Biochemical data are also presented in table 1 as means and respective standard deviations. There was no statistically significant difference between the groups for TC and LDLc. Significant differences for the control, IS, and CAD groups were observed relative to PAOD group $(\mathrm{p}<0.001)$ for HDLc plasma levels. Significantly higher levels of triglycerides were observed for CAD and PAOD groups than for controls. Apo A-I plasma levels in patients with CAD differed significantly from the control, IS, and PAOD patients ( $\mathrm{p}<$ 0.001 ). A significant difference was observed between the IS group in relation to control and PAOD groups $(p<0.001)$ for plasma apo B levels. The apo B/Apo A-I ratio in IS and CAD groups differed significantly from the control and PAOD groups $(\mathrm{p}<0.001)$. However, as these results were analyzed by using a binary logistic regression model, no described parameter on table 1 appeared to be associated to development of IS, CAD or PAOD. The distribution of values of Apo B/Apo A-I ratios in the groups studied is presented in figure 1 .

\section{Apo B/apo A-I according to risk factors}

The averages of apo B/apo A-I ratio were calculated for the four groups in the presence of risk factors. Significant differences between smoking and non-smoking patients in groups IS $(\mathrm{p}=0.03)$ and CAD $(\mathrm{p}<$ 0.01 ) were observed. With respect to the other risk factors, no significant differences were observed for the apo B/apo A-I ratio in the groups studied.

\section{Correlations between the biomarkers}

There were positive correlations between apo B and LDLc $(\mathrm{r}=0.53, \mathrm{p}<0.0001)$ and between apo A-I and HDLc $(\mathrm{r}=0.44, \mathrm{p}<0.001)$, considering all 124 participants, as has been reported previously for the methods utilized (18). The apo B/apo A-I ratio showed positive and significant associated with apo B levels ( $\mathrm{r}$ $=0.91, \mathrm{p}<0.0001)$, TC levels $(\mathrm{r}=0.63, \mathrm{p}<0.0001)$, TG levels $(\mathrm{r}=0.51, \mathrm{p}<0.0001)$, and plasma LDLc levels $(r=0.50, p<0.0001)$. Negative correlation was also observed between apo B/apo A-I ratio and plasma apo A-I levels $(\mathrm{r}=-0.49, \mathrm{p}<0.0001)$. However, no significant correlation was observed between apo $\mathrm{B} / \mathrm{apo}$ A-I ratio and HDLc levels $(\mathrm{r}=-0.02, \mathrm{p}=$ $0.8134)$. 
Table 1. Characterization of the studied groups according to sex, age, and biochemical parameters (expressed as mean and standard deviation) and presence of the risk factor (percentage).

\begin{tabular}{lcccc}
\hline & Control & IS & CAD & PAOD \\
$\mathrm{n}(\mathrm{M} / \mathrm{F})$ & $38(18 / 20)$ & $26(10 / 16)$ & $30(17 / 13)$ & $30(14 / 16)$ \\
Age (years) & $37 \pm 17$ & $31 \pm 15$ & $61 \pm 10^{*}$ & $64 \pm 13^{*}$ \\
Smoking & - & $8(31 \%)$ & $10(33 \%)$ & $23(77 \%)^{\ddagger \S}$ \\
Hypertension & - & $10(38 \%)$ & $26(87 \%)^{\ddagger}$ & $24(80 \%)^{\ddagger}$ \\
Family history & $8(21 \%)$ & $8(31 \%)$ & $13(43 \%)$ & $23(77 \%)^{*} \S$ \\
Diabetes mellitus & - & - & $3(10 \%)$ & $17(57 \%)^{\S}$ \\
TC (mg/dl) & $179 \pm 41$ & $208 \pm 61$ & $203 \pm 42$ & $188 \pm 45$ \\
HDLc (mg/dl) & $47 \pm 9$ & $46 \pm 11$ & $47 \pm 8$ & $35 \pm 11^{* \neq \S}$ \\
LDLc (mg/dl) & $111 \pm 36$ & $117 \pm 53$ & $123 \pm 37$ & $125 \pm 38$ \\
TG (mg/dl) & $102 \pm 54$ & $129 \pm 71$ & $165 \pm 75^{*}$ & $166 \pm 128^{*}$ \\
Apo A-I (mg/dl) & $151 \pm 10$ & $147 \pm 10$ & $125 \pm 7^{* \ddagger \S}$ & $148 \pm 14$ \\
Apo B (mg/dl) & $70 \pm 15$ & $89 \pm 21^{* *}$ & $80 \pm 16$ & $69 \pm 13$ \\
Apo B/Apo A-I & $0.46 \pm 0.1$ & $0.62 \pm 0.2 * *$ & $0.64 \pm 0.1 * *$ & $0.47 \pm 0.1$ \\
\hline
\end{tabular}

$\mathrm{n}=$ sample size $\mathrm{M}=$ male, $\mathrm{F}=$ female, $\mathrm{TC}=$ total cholesterol, $\mathrm{HDLc}=\mathrm{HDL}$ cholesterol, $\mathrm{LDLc}$ $=\mathrm{LDL}$ cholesterol, $\mathrm{TG}=$ triglycerides, $\mathrm{Apo} \mathrm{A}-\mathrm{I}=$ apolipoprotein $\mathrm{A}-\mathrm{I}, \mathrm{Apo} \mathrm{B}=$ apolipoprotein $\mathrm{B}, \mathrm{IS}=$ ischemic stroke, $\mathrm{CAD}=$ coronary artery disease, $\mathrm{PAOD}=$ peripheral arterial obstructive disease. Significant differences $(p<0.01)$ among the groups are represented by the symbols $\left(^{*}\right)$ vs. control, $\left(^{\ddagger}\right)$ vs. IS, $(\S)$ vs. CAD, and $\left(^{\ddagger}\right)$ vs. PAOD.

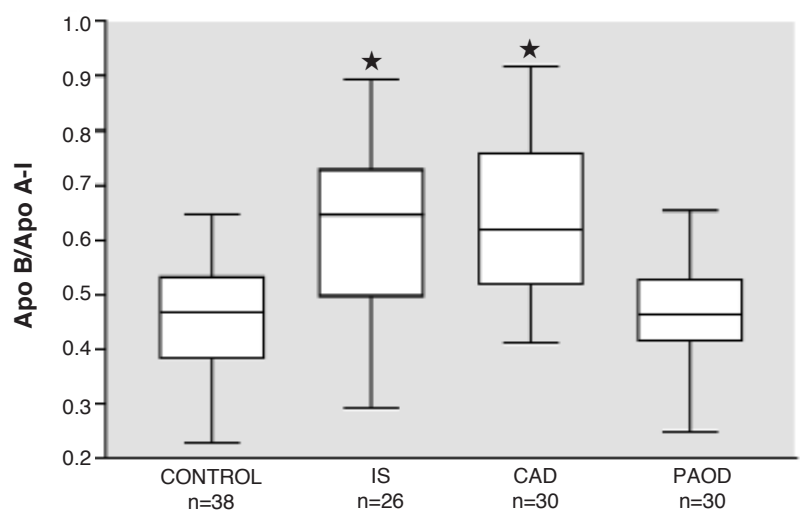

Figure 1. The distribution of the apoB/apoA-I ratios in controls, IS (ischemic stroke), CAD (coronary artery disease), and PAOD (peripheral arterial obstructive disease) groups. ( $\star$ ) Indicates significant difference in relation to the control and PAOD groups $(p<0.001)$. Each box represents the median and interquartile range of values, with the I bars (whiskers) extended to the minimum and maximum values.

\section{DISCUSSION}

Apolipoprotein metabolism is closely associated with the development of atherosclerosis, and the apo $\mathrm{B} /$ apo A-I ratio has been shown to be a better marker for prediction of cardiovascular events and prognosis than other classical lipid parameters such as TC and LDLc (19). In agreement, in the present study, the averages for TC and LDLc for all groups did not present significant differences (table 1 ). Thus, the above- mentioned parameters did not provide further information on the lipid alterations among patients with the three diseases.

The levels of HDLc were significantly lower in patients with PAOD than in patients with IS and CAD or in normal subjects. A possible explanation for this finding may be the fact that the PAOD group presented a high number of diabetic individuals (table 1 ). A high prevalence of dyslipidaemia in diabetic patients is described in the literature (16), and the association of the two conditions could aggravate the dyslipidaemia by synergism. TG plasma levels were significantly higher in CAD and PAOD groups than in the control group, but the latter had a lower mean age than the CAD and PAOD groups (table 1), a fact that may have contributed for such a finding.

This study demonstrated significantly lower apo A-I plasma levels for the apolipoprotein profile in the CAD group, when compared with the control, IS, and PAOD groups (table 1). Thus, the reduction in apo AI levels correlated with the presence of CAD in the group of patients analyzed, while apo B did not provide further information. These data contribute for high apo B/apo A-I ratio showed for CAD patients. High apo B levels, as well as low apo A-I levels and a high apo B/apo A-I ratio, have consistently been associated with the CAD risk $(9,19)$. Meisinger et al. $(20)$ demonstrated a strong prediction of $\mathrm{CAD}$ by the apo $\mathrm{B}$ and the apo B/apo A-I ratio in men and women, while apo A-I did not contribute significantly for the coronary event in the MONICA/KORA study. On the other hand, according 
to the Luc et al. (21) study, apo A-I has been shown to be an independent risk factor for CAD. Westerveld et al. (22) demonstrated that apo B plasma levels were superior to plasma levels of TC, HDLc, LDLc, TG, and apo A-I for predicting CAD in women. In the Kim et al. (23) study, only the apo B/apo A-I ratio was shown to be an additional tool for predicting CAD, when plasma levels of TC, LDLc, HDLc, apo A-I, and apo B were analyzed together in men and women with low risk for cardiovascular diseases.

In contrast to the vast literature available for the $\mathrm{CAD}$ risk, the association of apo $\mathrm{B}$, apo $\mathrm{A}-\mathrm{I}$, and the apo $\mathrm{B} /$ apo A-I ratio in IS and PAOD is still not completely consolidated. Relatively fewer studies correlated these parameters with atherosclerotic diseases other than CAD. In this study, we found increased plasma apo B levels in IS group (table 1). Although apo A-I levels did not differ, the apo B/apo A-I ratio was significantly raised in patients with IS. Walldius et al. (24) recently reported a strong association between the apo B/apo AI ratio and the risk of a fatal stroke, ischemic or not, in a prospective study involving a large number of subjects, suggesting that this association would be similar to that observed for MI.

All patients evaluated in this study had confirmed diagnosis of atherosclerotic diseases, but the apo B/apo A-I ratio was not significantly high in PAOD group. Contrasting to our findings, McConathy et al. (25) demonstrated that the apolipoproteins A-I and B differed significantly in PAOD from normal individuals in a group of women, when data was analyzed together with TC and TG dosages, while Schmidt et al. (26) demonstrated that the apo B/apo A-I ratio is associated with increased risk of cardiovascular diseases and femoral artery atherosclerosis as well, which showed to be a better marker than the LDLc. In the present study, the LDLc/HDLc ratio in PAOD group appeared significantly higher than in the other groups (data not shown), suggesting that for PAOD, the LDLc/HDLc ratio was more important than apo B/apo A-I ratio. However, it should be noted that PAOD patients were significantly older, smokers, and diabetics (table 1). In addiction, atherosclerotic plaques in PAOD have more fibrotic components than in CAD or IS, which presents more lipid components (27), what might partly justify this finding.

It was tempting, in spite of the small number of subjects, to check if the apo B/apo A-I ratio was associated with presence or absence of risk factors among patients. When patients were later grouped according to these criteria, a significant association was found between smoking and the apo B/apo A-I ratio in patients with IS and CAD. Indeed, the INTERHEART study (28) showed that the apo B/apo A-I ratio together with smoking explained $75 \%$ of the variability of the rate of acute MI worldwide. Although hypertension and family history are classical risk factors for atherosclerotic diseases (2), the fact that significant differences in apo B/apo A-I ratio were not found for hypertension or family history presence might be associated with the small sampling size analyzed in the present study.

It is of note the fact that apolipoprotein measurement presents some methodological advantages over the quantification of lipids and lipoproteins, as well as over the estimate of LDLc by the Friedewald equation (13). Apolipoproteins can be measured directly in the plasma by accurate, internationally standardized methods $(11,12)$, and their values show small biological variation and small fluctuations in response to stimulation of metabolic control. Walldius \& Jungner (29) suggested cut-off points of 0.9 and 0.8 for men and women, respectively, for the apo $\mathrm{B} / \mathrm{apo} \mathrm{A}-\mathrm{I}$ ratio in the evaluation of atherosclerotic risk. Although significantly higher apo B/apo A-I ratios were detected in patients with CAD or IS than healthy subjects of the present study, the average values for apo B/apo A-I ratio detected were lower than these proposed cut-off points (table 1), according to MONICA/KORA study (20).

Because our observations are based on a small group of patients, it is difficult to propose a cut off value for apo B/apo A-I ratio to be taken as significant for each disease and would require a larger population analysis. Another important limitation is the fact that we evaluated only associations, not prediction or causation, and we could not explain why the HDL cholesterol and apo A-I values were reversed between the CAD and PAOD groups, since the cholesterol and protein components of HDL should track fairly closely. However, in the present data set, this did not occur. Finally, our finding is related to a group of patients not matched for age, a parameter that may affect apolipoprotein levels.

In conclusion, the apo B/apo A-I ratio was important for identifying an increased trend for coronary and cerebral atherosclerosis, in spite of the fact that heterogeneous distribution of apo B and apo A-I levels was observed among the different groups. In spite of the increased trend for apo B/apo A-I ratio in IS and CAD groups, the studied variables cannot be considered in an isolated way, given as those parameters were analyzed together by a binary logistic regression, no association has been demonstrated. Additional studies are required to extend the evaluation of apo B/apo A-I ratio in different populations and in different types of atherosclerosis events. Such studies may contribute for a more precise standardization of this parameter as a marker of atherosclerotic risk in different anatomical sites. 


\section{ACKNOWLEDGEMENTS}

The authors are very grateful to the physicians Dr. Cirilo Pereira da Fonseca Neto, Dr. José Carlos Faria Garcia, Dr. Jamil Abdala Saad, Dr. Maria Elizabeth Rennó de Castro Santos, and Dr. Daniel Dias Ribeiro for patient selection. We also thank Laboratel Laboratório de Análises Clínicas for technical support. This work received financial support from CNPq, CAPES, and FAPEMIG.

\section{REFERENCES}

1. Libby $P$, Ridker PM, Maseri A. Inflammation and atherosclerosis. Circulation 2002;105:1135-43.

2. World Health Organization. Health topics. Available at $<$ http://www.who.int/cardiovascular_diseases/en/>. Accessed in: November 2006.

3. McNamara JR, Warnick GR, Cooper GR. A brief history of lipid and lipoprotein measurements and their contribution to clinical chemistry. Clin Chim Acta 2006;369:158-67.

4. Cantin B, Despres JP, Lamarche B, Moorjani S, Lupien PJ, Bogaty $P$, et al. Association of fibrinogen and lipoprotein(a) as a coronary Heart disease risk factor in men (The Quebec Cardiovascular Study). Am J Cardiol 2002;89:662-6.

5. Vaverkova H, Frohlich J, Jackuliakova D, Novonty D. Comparison of apolipoprotein B and plasma lipids as targets for lipid lowering treatment. Clin Biochem 2005;38:509-13.

6. Roeters Van Lennep JE, Westerveld T, Roeters Van Lennep HWO. Apolipoprotein concentrations during treatment and recurrent coronary artery disease events. Arterioscler Thromb Vasc Biol 2000;20:2408-13.

7. Sniderman AD, Furberg CD, Keech A. Apolipoproteins versus lipids as indices of coronary risk and as targets for statin treatment. Lancet 2003;361:777-80.

8. Wagner AM, Ordonez-Llanos J. Apolipoproteins and prediction of fatal myocardial infarction. Lancet 2002;359:1863-4.

9. Walldius G, Jungner I. The apo B/apo A-I ratio: a strong, new risk factor for cardiovascular disease and a target for lipidlowering therapy - a review of the evidence. J Intern Med 2006;259:493-519.

10. Sniderman AD, Junger I, Holme I, Aastveit A, Walldius G. Errors that result from the TC/HDL $C$ ratio rather than the apo $\mathrm{B} / \mathrm{apo} \mathrm{A}-\mathrm{I}$ ratio to identify the lipoprotein-related risk of vascular disease. J Intern Med 2006;259:455-61.

11. Marcovina SM, Albers JJ, Henderson LO, Hannon WH. International Federation of Clinical Chemistry standardization project for measurements of apolipoproteins A-I and B. III Comparability of apolipoprotein A-I values by use of international reference material Clin Chem 1993:39:773-81.

12. Marcovina SM, Albers JJ, Kennedy H, Mei JV, Henderson LO, Hannon WH. International Federation of Clinical Chemistry standardization project for measurements of apolipoproteins AI and B. IV Comparability of apolipoprotein B values by use of international reference material. Clin Chem 1994;40:586-92.

13. Marcovina S, Packard CJ. Measurement and meaning of apolipoprotein A-I and apolipoprotein B plasma levels. $J$ Intern Med 2006;259:437-46.

14. Benchimol A, Bernard V, Pillois X, Hong NT, Benchimol D, Bonnet $\mathrm{J}$. Validation of a new method of detecting peripheral artery disease by determination of ankle-brachial index using an automatic blood pressure device. Angiology 2004;55:127-34.

15. Brazilian Society of Cardiology. III Brazilian Guidelines on Dyslipidemias and Guidelines of Prevention of Atherosclerosis. Arq Bras Cardiol 2001;77 (suppl III):1-48

16. Genuth S, Alberti KG, Bennett P, Buse J, Defronzo R, Kahn R, et al.; Expert Committee on the Diagnosis and Classification of Diabetes Mellitus. Follow-up report on the diagnosis of diabetes mellitus. Diabetes Care 2003;26(11):3160-7.
17. Chobanian AV, Bakris GL, Black HR, Cushman WC, Green LA, Izzo JL Jr, et al.; National Heart, Lung, and Blood Institute Joint National Committee on Prevention, Detection, Evaluation, and Treatment of High Blood Pressure; National High Blood Pressure Education Program Coordinating Committee. National High Blood Pressure Education Program Coordinating Committee. The seventh report of the Joint National Committee on prevention, detection, evaluation, and treatment of high blood pressure: The JNC 7 report. JAMA 2003;289:2560-72.

18. Lima LM, Carvalho MG, Soares AL, et al. Apolipoproteins A-I and $B$ plasma levels correlations with lipid profile in subjects with type 2 diabetes mellitus. J Bras Patol Med Lab 2005;41:411-7.

19. Thompson A, Danesh J. Associations between apolipoprotein $\mathrm{B}$, apolipoprotein $\mathrm{Al}$, the apolipoprotein $\mathrm{B} / \mathrm{Al}$ ratio and coronary heart disease: a literature-based meta-analysis of prospective studies. J Intern Med 2006;259:481-92.

20. Meisinger $\mathrm{C}$, Loewel $\mathrm{H}$, Mraz W, Koenig W. Prognostic value of apolipoprotein $B$ and $A-I$ in the prediction of myocardial infarction in middle-aged men and women: results from the MONICA/KORA Augsburg cohort study. Eur Heart J 2005;26:271-8.

21. Luc G, Bard JM, Ferrières J, Evans A, Amouyel P, Arveiler D, et al. Value of HDL cholesterol, apolipoprotein A-I, lipoprotein $A-I$, and lipoprotein A-I/A-II in prediction of coronary heart disease. The PRIME Study. Arterioscler Thromb Vasc Biol 2002;22:1155-61.

22. Westerveld $H T$, van Lennep JE, van Lennep HW, Liem $A H$, de Boo JA, van der Schouw YT, et al. Apolipoprotein B and coronary artery disease in women. A cross-sectional study in women undergoing their first coronary angiography. Arterioscler Thromb Vasc Biol 1998;18:1101-7.

23. Kim HK, Chang SA, Choi EK, Kim YJ, Kim HS, Sohn DW, et al. Association between plasma lipids, and apolipoproteins and coronary artery disease: a cross-sectional study in a low-risk Korean population. Int J Cardiol 2005;101:435-40.

24. Walldius G, Aastveit AH, Jungner I. Stroke mortality and the apo B/apo A-I ratio: results of the AMORIS prospective study. J Intern Med 2006;259:259-66.

25. McConathy WJ, Greenhalgh RM, Alaupovic P, Woolcock NE, Laing SP, Lund V, et al. Plasma lipid and apolipoprotein profiles of women with two types of peripheral arterial disease. Atherosclerosis 1984;50:295-306.

26. Schmidt C, Fagerberg B, Wikstrand J, Hulthe J. Apo B/apo AI ratio is related to femoral artery plaques and is predictive for future cardiovascular events in healthy men. Atherosclerosis 2006;189(1):178-85.

27. Stary HC, Chandler AB, Dinsmore RE, Fuster V, Glagov S, Insull $\mathrm{W} \mathrm{Jr}$, et al. A definition of advanced types of atherosclerotic lesions and a histological classification of atherosclerosis. A report from the Committee on Vascular Lesions of the Council on Arteriosclerosis, American Heart Association. Arterioscler Thromb Vasc Biol 1995;15(9):1512-31.

28. Yusuf S, Hawken S, Öunpuu S, Dans T, Avezum A, Lanas F, et al.; INTERHEART Study Investigators. Effect of potentially modifiable risk factors associated with myocardial infarction in 52 countries (the INTERHEART study): case-control study. Lancet 2004;364:937-52.

29. Walldius G, Jungner I. Apolipoprotein B and apolipoprotein A-I: risk indicators of coronary heart disease and targets for lipid-modifying therapy. J Intern Med 2004;255:188-205.

\section{Endereço para correspondência:}

Maria das Graças Carvalho

Faculdade de Farmácia

Universidade Federal de Minas Gerais

Av. Antônio Carlos 6627

31270-901 Belo Horizonte, MG

Fax: (31) 3499-6985

E-mail: mgcarvalho@farmacia.ufmg.br 